Revista Iberoamericana, Vol. LXXV, Núm. 231, Abril-Junio 2010, 377-391

\title{
DETECCIÓN PÚBLICA / DETECCIÓN PRIVADA: EL PERIODISTA COMO DETECTIVE EN LA NARRATIVA POLICÍACA NORFRONTERIZA
}

\author{
POR \\ Juan Carlos Ramírez-Pimienta \\ San Diego State University-Imperial Valley \\ José Pablo Villalobos \\ Texas A\&M University
}

-¿También eres periodista?
-No, mi ramo es diferente.
$\quad$ Ifigenio Clausel (Ramírez Heredia 97)
...no era detective ni me gustaba serlo, que una cosa
era escribir y otra andar de metiche...

La morena (Laurini 158)

Al hacer un recorrido por la narrativa policíaca del norte de México se observa que en ésta raramente aparece la figura del detective, no digamos convencional o analítico, sino ni siquiera la figura del detective duro “a la Belascoarán” de Paco Ignacio Taibo II. ${ }^{1}$ Ante este vacío de vocación detectorial oficial, en muchas ocasiones, el espacio es ocupado tanto por individuos de la sociedad civil ${ }^{2}$ como por periodistas que tratan de inyectar un poco de justicia -de cualquier tipo- en un entorno confuso y violento. Los periodistas protagonistas de las narrativas policíacas norteñas, muchas veces inspirados en personajes de la vida real, saben que una justicia clara y prístina es muy difícil de obtener pero a la vez están conscientes de que cualquier fragmento de justicia que se obtenga es mejor que nada y continúan así con su labor de exposición de los agentes delictivos. Mientras que exponer no es lo mismo que castigar, en las narrativas de la región, con frecuencia, es a lo único que los periodistas pueden aspirar, aun cuando esto implique arriesgarlo todo.

1 A no ser que esté de paso por la región, como sucede en su novela Sueños de frontera.

2 Por ejemplo, el investigador honorario de la Comisión Legislativa para los Derechos Humanos y miembro de Amnistía Internacional que protagoniza Mezquite Road y los otros textos de la saga de Morgado de Gabriel Trujillo Muñoz; el cibernauta Awik en Los Ahogados no saben flotar, de Imanol Caneyada, y el ingeniero y profesor universitario Francisco Reyes Ibáñez de Algunos crímenes norteños y Otras caras del paraíso, de Francisco José Amparán. 
Si bien en otras tradiciones literarias el periodista y el detective confluyen (quizás el ejemplo más famoso sea A sangre fría de Truman Capote), en la mayoría de los casos, el reportero se encarga más bien de dar a conocer las motivaciones del criminal, no tanto la identidad de éste. Usualmente, la historia comienza en retrospectiva, es decir, una vez que el criminal ha sido identificado y se encuentra preso, éste le cuenta al periodista su historia. En el caso de los periodistas norteños, tanto de la ficción como de la vida real, no sólo son los encargados de informar acerca de los crímenes (la labor reporteril por excelencia) sino muchas veces de hacer ellos mismos la labor "policíaca”, la pesquisa, poniendo así su vida en peligro. Es bien sabido que, en la vida norteña, el periodismo de denuncia ha sido una sentencia de muerte para numerosos reporteros. ${ }^{3}$

La imagen del periodista norteño como una especie de detective "duro" se hace aún más tangible en el imaginario social si consideramos que inclusive algunas autoridades han comenzado a recomendar que porten armas para su protección personal. Lo anterior sucedió en el estado de Tamaulipas, donde, de acuerdo a la organización Reporteros sin Fronteras, las autoridades, ante el inminente peligro que conlleva el ejercer la profesión, han declarado que lo mejor sería que aquellos periodistas que teman por su vida presentaran una petición para llevar armas. ${ }^{4} \mathrm{La}$ organización ha manifestado preocupación especial por las condiciones de peligro para los periodistas en la frontera con Estados Unidos por "la ola de violencia sufrida por la prensa en la región, donde son numerosos los tráficos de todo tipo" (Reporteros). No es para menos: los tres periodistas asesinados en México en el año 2004 ejercían su labor en estados norfronterizos.

En este ensayo haremos un recorrido por la figura del periodista como agente detectorial en cuatro obras de la narrativa policíaca del norte de México. Un libro de denuncia publicado en 1911 y tres novelas publicadas al filo del milenio. Las obras son: ;Crimen monstruoso!: un periodista descubre el tremendo parricidio en Mazatlán, prisión del periodista al denunciar al parricida y sus cómplices, historia verídica y comprobada de este crimen sensacional (1911), Morena en rojo (1994), La frontera huele a sangre (2002) y No me da miedo morir (2003). Estas obras tienen como característica común que los agentes investigadores y protagonistas son periodistas, quienes, ante la complicidad (o en el mejor de los casos la indiferencia) de los responsables de la procuración de justicia, deciden hacer ellos mismos la pesquisa. En las cuatro narrativas quedan de manifiesto las trabas impuestas al

3 Según escribe Pamela Hartman, el "narcotráfico es la nota más importante de la frontera [...] y no está bien cubierto ni por la prensa de Estados Unidos ni por la de México, a causa del miedo [...]." Dice también que el riesgo es más significativo para los reporteros de diarios pequeños que no tienen el peso de un medio como The New York Times o Proceso: "A veces te sientes como si estuvieras absolutamente aislado, sin ninguna protección, armado sólo con una pluma y un cuaderno”.

4 Página Web de Reporteros sin Fronteras, http://www.rsf.org/article.php3?id_article=13113.

Revista Iberoamericana, Vol. LXXVI, Núm. 231, Abril-Junio 2010, 377-391 ISSN 0034-9631 (Impreso) ISSN 2154-4794 (Electrónico) 
conocimiento y a la difusión de los crímenes así como las consecuencias, muchas veces trágicas, para los protagonistas. Asimismo, las obras invariablemente muestran que cualquiera puede ser un cómplice del ilícito, aun aquellos que se presentan como aliados iniciales en la procuración de la búsqueda de la justicia.

La figura del periodista como detective no es exclusiva de la policíaca mexicana norteña. Ya María Elvira Bermúdez, uno de los pilares de la teoría, crítica y práctica de la narrativa policíaca mexicana del siglo xx, tenía en su personaje Armando Zozaya a un periodista que auxilia, complementa y también suplanta la labor de la policía. Lejos del detective “duro” de la tradición anglosajona, en boga al mediar el siglo xx, el detective periodista de Bermúdez es racional y analítico, el más analítico de los detectives mexicanos de acuerdo a Cathy Fourez. ${ }^{5}$ Zozaya, quien protagoniza la novela Diferentes razones tiene la muerte (1953) y la mayoría de los relatos de Muerte a la zaga (1986), observa y analiza a distancia, utilizando la psicología y la razón pura, rara vez se inmiscuye personalmente en los casos que le toca investigar.

Por otra parte, ya desde inicios del siglo xx, encontramos una temprana narrativa norteña que tiene a un periodista como detective, donde se narran las consecuencias que resultan de inmiscuirse en asuntos "oficiales”. Nos referimos a una obra que podría considerarse una de las primeras narrativas policíacas norteñas publicada en forma de libro. Si bien basada en un caso real, su lectura es la narración de un caso resuelto por su protagonista, un periodista metido a detective que consigue desentrañar el misterio de la muerte de un acaudalado ranchero sinaloense a principios del siglo xx. ${ }^{6}$ En el libro de largo título, iCrimen monstruoso!: un periodista descubre el tremendo parricidio en Mazatlán, prisión del periodista al denunciar al parricida y sus cómplices, historia verídica y comprobada de este crimen sensacional publicado en 1911, por Ramón P. Buxó, encontramos ya a un periodista encarcelado -el mismo Buxó- por investigar a contracorriente de la política. Como si se tratase de una nota roja cotidiana de la actualidad del norte y la frontera mexicanos, en el libro-denuncia encontramos que las autoridades responsables de promover la justicia son cómplices del crimen y complotan para encarcelar y propiciar la muerte del periodista que se atrevió a desafiar la versión oficial de la muerte del próspero don Albino Ruiz: "El cabo de la policía [...] avisó por teléfono a la Prefectura Política y de allí dieron orden al Alcalde que me cerrara herméticamente la puerta” (72).

En las primeras páginas del libro el ex-director del periódico La voz de Sinaloa deja muy en claro quiénes están relacionados con el crimen: jueces, prefectos

5 Literalmente, la crítica Cathy Fourez señala que "Armando Zozaya, journaliste de profession, est le plus intellectuel des détectives mexicains”.

6 Aunque sólo se corroboró su intuición cuando el culpable confesó, en artículo de muerte, su culpa ante un fraile.

Revista Iberoamericana, Vol. LXXVI, Núm. 231, Abril-Junio 2010, 377-391
ISSN 2154-4794 (Electrónico) 
políticos, la madre del asesino y el agente del ministerio público. Ataca además a buena parte del gremio periodístico ("La prensa muda"), pero da crédito a la "Prensa asociada de los Estados" sin cuya ayuda él hubiera sido "asesinado en la bartolina de cárcel de Mazatlán”. Así como muchas veces sucede en la actualidad, la ayuda solidaria que procuró la liberación del periodista Buxó provino de la presión de algunos miembros del gremio reporteril. Desconfiado de la justicia que le daba su libertad bajo caución pero que según él no garantizaba imparcialidad, decide escapar a la Ciudad de México:

Quebrantando la orden de arraigo del Juzgado, donde debía presentarme cada ocho días, puesto que estaba libre bajo caución, me embarqué con toda clase de precauciones a bordo del vapor "Limantour” con nombre supuesto el día 11 de septiembre y llegué a esta ciudad de México el 17 por la mañana, cuando estaban en su apogeo las fiestas del centenario. (78)

Parte del ejercicio de procuración de justicia de Buxó consistió en la publicación del libro que no sólo lo exoneraba a él sino que diseminaba y perpetuaba su denuncia. Por la narrativa misma, sabemos que el autor material del asesinato, el hijo de la víctima, de algún modo recibió su castigo pues falleció al poco tiempo, de muerte natural. No sabemos, empero, si los políticos cómplices fueron encarcelados y llevados a juicio. En este sentido, el libro de Buxó, al señalar textualmente su denuncia, funcionó como una punición alternativa. En esencia, esa es parte de la función de organizaciones como Reporteros sin Fronteras. La capacidad de actuar más allá de las fronteras les provee la posibilidad de difundir el ilícito y avergonzar así "globalmente" a las autoridades culpables, cómplices o complacientes, utilizando precisamente algunos de los mismos canales abiertos por la globalización, en este caso la globalización de la información. ${ }^{7}$ Este mecanismo es la piedra angular en que se sustenta la labor del periodista detective de la narrativa del norte mexicano. Como se sabe que el castigo oficial será muchas veces nulo o simbólico, la denuncia periodística sirve como un mecanismo de presión para lograr un poco de justicia.

\section{MORENA EN ROJO Y LOS LÍMITES DE LA DETECCIÓN PRIVADA}

¿Qué tan distinto es ser periodista de ser detective? Las citas empleadas como epígrafes de este artículo responden de forma tangencial a esta pregunta desde polos opuestos. Por un lado, el detective Ifigenio Clausel -protagonista de la narrativa

7 Ya Santiago Castro-Gómez, entre otros, ha teorizado al respecto al afirmar que "en tiempos de globalización, los medios son el terreno para el establecimiento del dominio de unos grupos sobre otros, pero también son, al mismo tiempo, el terreno apropiado para la resistencia contra ese dominio" (748).

Revista Iberoamericana, Vol. LXXVI, Núm. 231, Abril-Junio 2010, 377-391
ISSN 2154-4794 (Electrónico) 
policíaca de Rafael Ramírez Heredia- niega ser reportero y, por el contrario, la periodista y protagonista que narra Morena en rojo (1994), de Miriam Laurini, niega ser detective. Mientras que sería fácil decir que una de estas profesiones implica riesgos inexistentes en la otra, en el caso mexicano no es tan evidente saber en cuál de las dos se corre más peligro. De hecho, enfocándonos en la ciudad de Tijuana y en el caso particular del semanario político Zeta, se pueden encontrar suficientes pruebas para establecer que ser periodista es una profesión de alto riesgo: en 1988, Héctor Félix Miranda, su editor y co-fundador, fue asesinado. En 1997 Jesús Blancornelas, el otro co-fundador de Zeta, sobrevive un atentado que lo deja gravemente herido. ${ }^{8}$ No corre la misma suerte Francisco J. Ortiz Franco, también editor de Zeta, quien en 2004 es presuntamente asesinado por publicar y hacer denuncias sobre la situación del narcotráfico tijuanense. Lejos de los mitos y leyendas propagadas por el narcocorrido, las muertes y atentados en contra de estos y otros periodistas hacen concreta la seriedad de la labor a la que entregan literalmente sus vidas.

Es en estas mismas coordenadas norfronterizas en donde la protagonista y narradora anónima de Morena en rojo, de la escritora "argenmex" Miriam Laurini, se abre espacio como periodista de compromiso. En una frontera norte exenta de detectives, tanto de las propias autoridades como del sector privado, es la misma periodista quien debe hacerse de varias artimañas para intentar resolver crímenes que de otra manera no se logran aclarar. Tal y como sus héroes pertenecientes al mismo gremio, la "morena" debe meterse de lleno a las circunstancias sociales que la rodean para poder ser una corresponsal "de guerra"; ya no de guerras en el extranjero, sino de los combates que acechan a los grupos minoritarios que habitan el mundo cotidiano norfronterizo: "No quería ir a ninguna guerra que no fuera mía [...]. Cruzarme de mojada y saber qué se siente, una opción. Trabajar de obrera y saber qué se siente, otra opción. Esa era mi guerra” (96).

Quizá por conocer a fondo su profesión pero principalmente por el compromiso ético-moral que siente por gentes que comparten su posición marginal -tanto por ser mujer como por ser de tez oscura- ${ }^{9}$ la morena comenta en varias instancias su posición ante la labor de todo periodista. Mientras que se describe como "una periodista provinciana, del montón, lejos de la fama y el reconocimiento que alguna vez tanto me importaron" agrega que "Afortunadamente lo que no ha dejado de importarme es trabajar con honestidad y decir todas las verdades que me dejan publicar. Trabajar para los demás, de esta manera, debe ser lo que amo de mi

8 Luis Lauro Valero Elizaldi, chofer y guardaespaldas de Blancornelas, muere acribillado por las armas de alto poder utilizadas en el enfrentamiento.

9 La cuestión de la marginación a nivel extratextual se manifiesta en el caso de la propia Laurini quién, igual que escritores como Mempo Giardinelli y Rolo Diez, sale de la Argentina para exiliarse en México.

Revista Iberoamericana, Vol. LXXVI, Núm. 231, Abril-Junio 2010, 377-391
ISSN 2154-4794 (Electrónico) 
oficio” (9-10). Aunque su compromiso con los demás es lo que más le importa de su trabajo, también reconoce que una cosa es contar lo que quiere y otra lo que le es permitido incluir en sus notas. De hecho, como se da cuenta a lo largo de su carrera, mucho de lo que descubre se encubre por la misma prensa, que funciona al servicio tanto del gobierno como de diversos "peces gordos" que abundan en la frontera. Pero, en un sentido auto-referencial que explica la estructura a veces disgregada de la novela, lo que no se publica en los periódicos es lo que compone el texto. Lo importante aquí es reconocer que Morena en rojo pareciera componerse de esas hojas sueltas, de esas voces e historias personales que jamás se dan a conocer en la nota impresa en los diarios que la emplean como reportera.

El conflicto entre lo que quiere contar y lo que le es permitido se da en lo que la morena llama la matización. De hecho, salvo escasas excepciones, todo lo que escribe es sujeto de la censura de sus editores. Consciente de lo que se espera de ella, a lo largo de la novela juega con la idea de encubrir y descubrir lo que atestigua anticipando los parámetros de lo aceptable según sus editores. Tal es el caso de lo ocurrido cuando es enviada a cubrir un campamento de refugiados guatemaltecos en la frontera sur de México; aun cuando lo que presencia es deplorable, "no me lancé contra los molinos de viento. Hice una crónica matizada, matices, matices con sones de vals...en vez de vomitar a gusto me atraganté con los matices” (46-47). Como resultado de su mesurado reportaje, el director del periódico la felicita, le promete un aumento de sueldo diciéndole "así debe escribirse, muchacha. Pronto será una periodista destacada y cuando llegue ese momento la vamos a perder; la van a llamar al DF y tendrá que irse...” (47). Sin embargo, mientras que el reportaje se depura con los matices, la novela en sí recupera lo que presencia y lo rescata del olvido para el lector.

Si para redactar su reportaje sobre indocumentados guatemaltecos la morena se autocensura anticipando los límites de sus editores, el crimen con el cual abre la novela requiere de otro tipo de contemplación. El caso de María Crucita, quien llega a Nuevo Laredo con la esperanza de cruzar a Estados Unidos en busca de mejor vida, exige una matización que supera la autocensura -a la cual se recurre para los beneficios del periódico, sus editores y quienes ocupan los peldaños del poder. El crimen en cuestión, el asesinato del Comandante Videla, sacude a la población fronteriza de Nuevo Laredo por ser éste un hombre de gran reconocimiento a nivel local; un agente que "era justo con los pobres y aceptaba mordidas de los ricos, de los narcos, de los coyotes” (12). En el transcurso de su investigación para la nota roja que debe escribir, la morena descubre que el asesino del comandante Videla es la misma María Crucita, quien fue encaminada a la prostitución por Videla cuando éste era un joven. Al dar con el asesino, la morena enfrenta una crisis ético-moral y profesional que le presenta otro móvil para la matización de costumbre. Siguiendo

Revista Iberoamericana, Vol. LXXVI, Núm. 231, Abril-Junio 2010, 377-391
ISSN 2154-4794 (Electrónico) 
la habitual norma editorial, la prensa local se preocupa por la vida de la víctima, en este caso el comandante Videla. Pero mientras que los datos biográficos de Videla son asunto de primera plana en los diarios locales, en la novela se abrevian a dos párrafos. La narradora contrapone esta preocupación por el representante de la autoridad y le dedica casi el primer capítulo entero a la vida de María Crucita y a las causas que la encaminan a la frontera para abandonar México. Abriendo la novela de tal forma declara súbitamente el tema de solidaridad con los marginados: la historia de las víctimas es la que ocupa un lugar central, lugar que no aparece en las notas incluidas en la prensa local. Como dice la morena al concluir su investigación inicial: "regresé al periódico. Escribí la nota y veinte líneas para la primera plana. Los dejé discutiendo la cabeza. Lo que tenía ganas de escribir era la historia de María Crucita” (17). Cuando por fin descubre que es ésta la asesina de Videla, y cuando establece que el motivo es vengarse por haberla introducido al mundo de la prostitución diez años antes, la morena se jacta de haberle ganado a las autoridades en su pesquisa oficial y redacta la nota que en su estimación le dará un pase a los grandes periódicos de la Ciudad de México. Pero, por el compromiso que siente con la víctima -que en este caso no es el occiso Videla, sino María Crucita- junta las cuartillas de su gran reportaje y las enciende con un cerillo. De tal forma, a la vez que descubre la verdad, la encubre para salvar a la víctima de las manos de la misma autoridad que seguramente se cobrará caro la muerte de uno de sus miembros. Sacrifica su propio éxito profesional, se autocensura, por la solidaridad que siente con María Crucita: no la delata y de tal forma la salva de la tortura y el encarcelamiento que le hubiera esperado.

Del mismo modo que la historia de María Crucita, como la de los refugiados guatemaltecos, no se hace pública en la prensa, Morena en rojo cuenta las experiencias de otros tantos seres marginados que buscan quién escuche su historia: "mujeres marginadas, desterradas, y abusadas que fueron víctimas de la sociedad mexicana" (Fernández 134). De allí que, además de ser una novela policíaca, "también de una manera testimonial, el texto se transforma en una etnografía de vidas que son víctimas de una sociedad donde el terror y la violencia dominan” (Fernández 146). Ese aspecto testimonial, generalmente ajeno al género policíaco, encuentra lugar en un texto que, más allá de resolver el crimen, busca dar voz a los protagonistas de vidas que acaban censuradas por no caber dentro de la nota roja o por ser demasiado pedestres para figurar en la primera plana de cualquier periódico. Esta detección privada de la experiencia del ser marginado es la que Miriam Laurini logra fijar bajo el lente de la detección pública con su novela Morena en rojo.

Revista Iberoamericana, Vol. LXXVI, Núm. 231, Abril-Junio 2010, 377-391
ISSN 2154-4794 (Electrónico) 
NO ME DA MIEDO MORIR Y EL COMPROMISO CON EL AMBIENTE NORFRONTERIZO

A raíz de la publicación en el año 2003 de la obra policíaca No me da miedo morir se percibe un cambio en la narrativa del sonorense Guillermo Munro. En anteriores obras, como en El camino del diablo, el escritor de Puerto Peñasco narra los esfuerzos por conquistar el desierto de Sonora y hacerlo transitable. En sus novelas, el ser humano es típicamente presentado como un héroe en constante lucha con la naturaleza. En No me da miedo morir, el villano ya no es tanto el difícil entorno natural como el propio ser humano que se empeña en destruirlo. El libro está dedicado a periodistas de denuncia y a biólogos ambientalistas. El propio autor ha sido miembro por más de veinte años de la asociación ambientalista Centro de Estudios del Desierto y el Océano.

La primera dedicatoria de la novela es a Benjamín Flores, periodista asesinado el 15 de julio de 1997 en la ciudad fronteriza de San Luis Río Colorado, Sonora. En el norte y la frontera mexicana, donde realidad y la ficción se confunden de manera especial, este joven periodista de 29 años y director del diario La prensa, fue acribillado a unos pasos de sus oficinas. De una camioneta en marcha descendió un sujeto que después de ametrallarlo volvió a su auto, recogió una pistola y regresó para rematarlo con otros tres tiros en la cabeza (Xanic). Poco antes de morir, Benjamín Flores publicó varias notas acerca de media tonelada de cocaína decomisada que desapareció mientras estaba asegurada en las oficinas de la Policía Judicial Federal, en San Luis Río Colorado. El periodista había cometido el "error" de reportar cómo una noche unos sujetos habían llegado en camiones y cargado la droga "custodiada" para luego irse tranquilamente. Los titulares de La prensa acusaron a policías y comandantes de estar coludidos con el crimen organizado. Algunos de los testigos incluso habrían dicho que los sujetos que se llevaron la droga parecerían ser soldados y que los camiones usados también se parecían a los usados por el ejército mexicano. Asimismo, los reportes insistieron en la relación del gobernador del estado de Sonora con personajes del crimen organizado. Esta no sería la primera ni la última vez que altos oficiales del gobierno sonorense fueran señalados como cómplices del narcotráfico. En la década de los ochenta, Rafael Caro Quintero, el célebre narcotraficante afincado en Caborca, señaló a varios funcionarios sonorenses como sus cómplices cuando fue hecho prisionero en 1985.

La segunda dedicatoria de la novela es al ya mencionado periodista y director del semanario bajacaliforniano Zeta, Jesús Blancornelas, quien sobrevivió a un atentado a manos de sicarios asociados al cartel de Tijuana en noviembre de 1997. A raíz del atentado, Jesús Blancornelas tuvo que estar constantemente protegido por un equipo de soldados que se convirtió en su guardia personal las 24 horas del

Revista Iberoamericana, Vol. LXXVI, Núm. 231, Abril-Junio 2010, 377-391
ISSN 2154-4794 (Electrónico) 
día durante el resto de su vida. ${ }^{10} \mathrm{El}$ atentado no minó la dedicación del periodista quien prosiguió su labor de denuncia, conservando y aun incrementado su papel como una de las fuentes de conocimiento y denuncia de las redes del narcotráfico nacional y de su conexión con agentes y jefes policíacos así como con políticos a todos los niveles. Cuando otros periodistas anunciaron que ya no investigarían sobre el narcotráfico sino que sólo se dedicarían a reportar las noticias, don Jesús anunció que comprendía las razones de sus colegas pero que él y su periódico continuarían con su labor (Blancornelas).

Hay tres líneas narrativas en No me da miedo morir: una es la narración desde el punto de vista de una vaquita marina (Phocoena Sinus). Las otras dos son más pertinentes para nuestro tema: una línea narrativa que se desarrolla a través de pequeños textos escritos como notas periodísticas de diversos diarios; estas son las secciones que contextualizan lo que está sucediendo en el país, presa del poder del narcotráfico. Por último, la tercera línea la forman los capítulos que van del 1 al 30 y que cuentan la historia de amor y aventuras de Cristóbal Santillánez, reportero del periódico El Centinela, y Gabriella Girardi, bióloga marina dedicada al estudio de la biósfera del Golfo de Santa Clara. Los dos tratarán de resolver los crímenes ecológicos y los crímenes contra la salud pública, ambos causados por los narcotraficantes.

Cristóbal y Gabriella se habían conocido varios meses antes, durante la inauguración de la Reserva de la Biósfera del Alto Golfo de California. El periódico de Cristóbal lo había mandado a cubrir el evento. Ahí inició una amistad que siguieron manteniendo por medio de contactos esporádicos, hasta que un día ella le pide que regrese a la reserva para investigar lo que está sucediendo en el Golfo de California, la muerte y endemias en diversas especies marinas de la región en peligro de extinción. Hay varias teorías que explicarían la muerte de los animales pero la que más los convence es la de la sustancia llamada NK 19, un químico fosforescente que está siendo utilizado para marcar el área donde deben dejar caer su carga las avionetas de los narcotraficantes. La carga es luego recogida por pescadores en lanchas rápidas. El químico, por otra parte, se queda en el Golfo contaminando todo lo que toca.

Después de muchos sufrimientos y peligros, la pareja y sus aliados logran detener a una parte de la organización criminal compuesta por agentes de la ley corruptos, tanto de México como de los Estados Unidos. Pero el golpe más fuerte lo da Cristóbal en su capacidad periodística. En las últimas líneas de la novela se nos anuncia que éste recibió un premio por parte de la Sociedad Interamericana de Prensa por escribir un reportaje denunciando cómo opera el narcotráfico en la región. Al atraer atención sobre las zonas desérticas sonorenses, el periodista

10 El periodista muere de cáncer en noviembre de 2006.

Revista Iberoamericana, Vol. LXXVI, Núm. 231, Abril-Junio 2010, 377-391
ISSN 2154-4794 (Electrónico) 
obliga a la organización delictiva a mudar sus operaciones. No me da miedo morir revela las tensiones y presiones que sufre la procuración de justicia en los estados norfronterizos. Esta novela negra hace una aguda crítica social, pero siempre reconociendo que el problema es muy complejo y difícil de resolver. Como trasfondo de la corrupción y la delincuencia se encuentra un país inmerso en una crisis económica que si bien no justifica lo ilícito sí ayuda a concebirlo en su entorno social. Muchos de los capítulos están escritos a manera de notas periodísticas y reflejan de manera realista los cientos que cada año se escriben en los diarios y semanarios, tanto de la región como aquellos de circulación nacional, reportando ajustes de cuentas entre narcotraficantes o algún escándalo político. El discurso periodístico y el novelístico se confunden en medio de una narcocultura donde ya poco sorprende, ya sea droga que desaparece de manos de autoridades locales o la filtración del narco en los altos niveles de procuración de justicia, tanto en México como en los Estados Unidos.

\section{LA FRONTERA HUELA A SANGRE Y LA MIRADA EXTERNA DE LA FRONTERA NORTE}

Si en los casos anteriores, tanto la morena de Laurini como el Cristóbal Santillánez de Munro tratan sus temas con un compromiso que rebasa las metas del reportaje o la publicación de sus hallazgos, el Sepu de la novela La frontera huele a sangre (2002) pertenece a otra estirpe de periodista como detective. En su novela policíaca, Ricardo Guzmán Wolffer tiene como protagonista a un reportero oriundo de la ciudad de México que, por un reportaje que le causa problemas a su periódico, es despachado como corresponsal a la ciudad de Nogales, Sonora. De tal forma, el "que no tenía la menor idea de dónde quedaba Nogales” y que incluso "nunca antes había escuchado hablar ese nombre" (8), repentinamente se halla en una situación incómoda en un mundo que le es totalmente ajeno. Al contrario de los textos de Laurini y de Munro, en donde los protagonistas pertenecen o se hacen parte del entorno en que laboran, Sepu es trasplantado a una región que, según su experiencia, sólo corrobora los estereotipos de la frontera del norte mexicano: "su caso es el de un narrador que observa la vida fronteriza desde una perspectiva sureña, centralista” (Trujillo, “Conflictos y espejismos” 32).

Al llegar a Nogales por primera vez, Sepu y su esposa encuentran una ciudad caracterizada por "bares de mala muerte" (32), tiendas de curios y tiraderos de basura. Sus habitantes masculinos, cuando no son cholos, portan la vestimenta norteña de botas vaqueras, esclavas de oro y "camisas de seda con motivos narquiles" (24). $\mathrm{Al}$ explorar la ciudad Sepu se percata de que

Revista Iberoamericana, Vol. LXXVI, Núm. 231, Abril-Junio 2010, 377-391
ISSN 2154-4794 (Electrónico) 
El panorama de las calles no era muy halagador. Después acabaría de entender. Nogales es ciudad de maquiladoras, en lo legal. En lo ilegal, bueno, como medio México, era zona del narco y del pollo [...]. Por eso viene a colación para entender un panorama donde el mayor porcentaje de la gente o es obrera... o es alguien en tránsito de llegar al otro lado de la línea fronteriza [...]. (31)

Este catálogo de tipos fronterizos, por lo tanto, se convierte en una visión de la frontera pública y externa plasmada en toda noticia relacionada al entorno norfronterizo. Mientras que Laurini y Munro a su vez presentan algo de ese aspecto público de la vida fronteriza en sus novelas, en ellas hay un compromiso personal que rebasa los estereotipos para dar atención a lo que no forma parte del imaginario social y que se nutre de la nota roja. Este no es el caso de La frontera huele a sangre, en donde el periodista, como un ser de fuera que no pertenece al entorno que describe, tiene un compromiso netamente profesional con el gremio al que pertenece.

$\mathrm{Al}$ establecerse en Nogales, Sepu de inmediato se propone buscar material para las notas que debe entregar a su diario:

Al llegar a la oficina, lo primero que se me ocurrió decirle a Panchita [la secretaria] fue el tema de mi artículo inicial: -El narco, Panchita, el narco es lo más candente que hay en el norte. Necesito hablar con alguien bien enterado de eso. (34-35)

A partir de ese momento, por suerte, intuición y otras coincidencias, Sepu descubre que en el transcurso normal del tráfico de indocumentados, drogas y órganos humanos, algo no anda como debe. Entre los migrantes que salen hacia el estado de Arizona, hay quienes mueren de manera misteriosa al cruzar la frontera y son repatriados en ataúdes sellados hasta sus pueblos, principalmente situados en el centro de México. Lo que descubre Sepu, atando cabos que encuentra a través de polleros, indocumentados y policías de ambos lados de la frontera como informantes, es que, al integrarse al país vecino, los indocumentados son entregados a un grupo desconocido que los asesina, les exhuma los órganos vitales y los reemplaza con elementos radioactivos antes de embalsamarlos y repatriarlos a México. Aunque se combinan el abuso y la muerte del indefenso -tema importante en Morena en rojo- con lo ecológico -tema de No me da miedo morir-, Sepu difiere en el trato de éstos por la distancia que manifiesta en su investigación y los móviles que están detrás de los resultados que logra.

Al contrario de vivir en carne propia lo que va descubriendo, su investigación en principio se reduce a entrevistar y observar a distancia. En las pocas instancias en que Sepu se hace partícipe directo de la historia que va desentrañando, sus motivos no se relacionan con la solidaridad con los sujetos involucrados, sino consigo

Revista Iberoamericana, Vol. LXXVI, Núm. 231, Abril-Junio 2010, 377-391
ISSN 2154-4794 (Electrónico) 
mismo. La primera ocasión en que se da esto es al reaccionar ante la amenaza de los policías corruptos, Tolano y Kihui. Estos reyes del hampa nogalense, al enterarse de las pesquisas de Sepu -que amenazan con desestabilizar su mundo- le hacen saber lo precaria que es su situación: "Olvídate de [...] los pollos. Ni te metas en esa bronca que se te puede cargar la chingada. A ti y a tu mujercita” (128). Al sentir que tanto su vida como la de su esposa peligran, aun cuando esté al margen del crimen que investiga, decide hacer algo para remediar la situación: "me tengo que echar ese pleito. Una cosa es que a mí me tiren a dar. Pero de ahí a que quieran perjudicar a mi mujer, pues ya calienta. Eso sí que ya es personal” (136). En vez de enfrentar directamente a Tolano y a Kihui, decide sobornar a quien les vende su dosis semanal de cocaína para alterar la pureza del polvo blanco que le compran. Aunque Tolano y Kihui mueren atropellados por el tren que atraviesa la ciudad de Nogales mientras persiguen a Sepu, éste se jacta de "poder ver que algo rojo comenzaba a caerles de la nariz" (168) poco antes de escuchar "el tronar de [sus] cuerpos contra la defensa del tren, cual insectos en parabrisas" (170). Puesto que acudir a las autoridades locales para levantar una demanda en contra de dos de sus miembros seguramente le hubiera traído consecuencias graves, Sepu toma el destino de Tolano y Kihui en sus propias manos para protegerse a sí mismo y a su mujer, a la vez que se libra de un gran impedimento para su investigación.

La segunda instancia en la cual Sepu se hace partícipe de carne y hueso de lo que investiga es cuando se hace pasar por pollo para cruzar como indocumentado a los Estados Unidos y así tratar de rastrear el paradero de quienes mueren al cruzar la frontera. Sin embargo no emprende esta peligrosa hazaña para saber qué se siente arriesgar la vida para cruzar al otro lado -este no es el tema de sus reportajes- sino con el fin de sacar alguna novedad que le permita avanzar en su investigación: “[...] me voy a meter de ilegal, a ver si así logro enterarme de algo” (147). Más que arriesgar su propia vida para salvar a los inmigrantes, el compromiso que despliega es de índole profesional. A ratos parece dejar a un lado las exigencias del gremio por una causa humanitaria, como lo demuestra la siguiente cita, en la cual intenta convencer a su informante estadounidense -el sargento Juan Pata, agente policial que asesora a la patrulla fronteriza- de continuar tras los malhechores:

No lo tomes a mal, pero de qué nos sirven esos datos sobre quién ayuda a quién. Necesitamos saber qué es lo que están haciendo. Hay que pasar a la ofensiva. La gente se está muriendo y nadie hace nada. Esto no puede seguir así, las autoridades deben hacer algo. El mundo nos necesita pues [...]. (146-147)

Sin embargo, aunque en apariencia los comentarios de Sepu parecieran ser de intención comprometida con el prójimo, su intención es manipular al sargento Pata para que éste lo acompañe en su investigación y de tal forma le brinde la seguridad

Revista Iberoamericana, Vol. LXXVI, Núm. 231, Abril-Junio 2010, 377-391
ISSN 2154-4794 (Electrónico) 
de un agente policial armado. Todo esto se torna más evidente con lo que comenta para sí mismo al encontrar a quienes le pueden dar información concreta del paradero de los presuntos criminales: "¿ ¿Se acuerdan de las direcciones? -les dije, pensando en que ahora sí estaba a un tris de hacerme famoso” (176). Asimismo, cuando parece que su investigación ha ahuyentado a los traficantes de materia radioactiva, hace a un lado por completo el hecho de que tal vez así haya salvado la vida de algún migrante: "No me digas que esta investigación se acabó, no puede ser. Yo quiero, yo necesito, un clímax en mi reportaje. Ahora sí que no se puede quedar así” (196). Gracias a su terquedad y a su astucia, Sepu logra suspender los ataques en contra de los indocumentados, pero esto no da para saciar su sed por el reportaje que, así como le traerá fama, quizá sea suficiente para congraciarlo con su periódico y de tal forma rescatarlo de su forzada estancia en la frontera norte. Cerca del final, a punto de dar con algunos de los culpables -entre ellos el mismo sargento Pata-, declara que "Ahora sí me voy a cubrir de gloria. Hasta editorialista me van a hacer, ya verás” (209).

Quizála mejor metáfora del distanciamiento que se percibe en el periodismo y la investigación de Sepu es la que se da respecto al embarazo de su esposa Teresita. Si en Morena en rojo y en No me da miedo morir existen compromisos con el entorno social y ecológico que habitan los protagonistas que viven directamente los estragos de ese ambiente norfronterizo, en La frontera huele a sangre no se percibe dicha conexión. Pasados los seis meses de embarazo, Sepu indaga sobre su papel en lo que se avecina. Le comenta a Teresita que "quisiera ser más participativo, apoyarte durante las contracciones, estar presente en el parto.” Cuando ella le replica que lo que debe hacer es informarse para poder ayudarle, Sepu implica que más que testigo ocular, quiere "saber que se siente todo eso" (189). Consciente de la imposibilidad de tal petición, el intercambio entre la pareja acaba en simple burla. ${ }^{11}$ Sepu no puede sentir en carne propia el dolor ajeno, por más que se informe al respecto. Su compromiso, aunque bien intencionado, no rebasa la superficie de alguien que ve desde afuera la imagen pública y estereotipada de la frontera norte de México.

\section{MÁs ALLÁ DEL TEXTO: DETECCIÓN PÚBLICA Y DETECCIÓN PRIVADA}

En las narrativas aquí analizadas se muestran las ataduras políticas y económicas nacionales e internacionales que erosionan la justicia. Ante la nula procuración de justicia convencional, las obras estudiadas proponen la indignación individual como el detonante de cambio. Tanto en ¡Crimen monstruoso! y Morena en rojo como

\footnotetext{
${ }^{11}$ Su esposa le contesta que "Si quieres saber cómo se siente una contracción, apriétate un testículo y cada cinco minutos le aflojas y lo vuelves a apretar. A lo mejor así medio te enteras” (189). Sepu sigue las instrucciones y acaba tirado en el suelo con harto dolor.
} 
en No me da miedo morir y La frontera huele a sangre es la figura del periodista la que trata de combatir lo ilícito. No es casual que los protagonistas participen de la diseminación de información porque las obras proponen que la diseminación y exposición del crimen es una de las pocas formas en que se puede combatir la injusticia y la impunidad en la policía del norte y su frontera. Sin embargo, si como ha dicho Gabriel Trujillo que en el "México del siglo xxi la policíaca es la novela costumbrista por excelencia" (Testigos de cargo 24), tendremos que pensar que la figura del periodista de carne y hueso dejará de ser, en buena medida, el modelo y patrón para los personajes de ficción policíaca. En agosto del 2005, algunos de los principales diarios norfronterizos anunciaron su decisión editorial de dejar de investigar el narcotráfico para tan sólo limitarse a dar reportes oficiales. Fue el mismo Jesús Blancornelas uno de los que dio aviso de la nueva política editorial:

Tienen temor al narcotráfico. Miedo de ser asesinados. Se sienten desprotegidos. Sin garantías. Por eso los periodistas ya no investigarán sobre la mafia ni escribirán en Hermosillo, Los Mochis, Nuevo Laredo, Mexicali y, parcialmente, Tijuana. Hay una excepción en Sinaloa. La decisión es personal. Fuera de allí, los editores o propietarios de periódicos acordaron no tocar el tema. ${ }^{12}$

El periodista bajacaliforniano agrega, contextualizando, que ésta es la primera vez "en los últimos cincuenta años que varios periódicos deciden no escribr sobre el narcotráfico por temor a los mafiosos y a la falta de seguridad oficial”. ${ }^{13} \mathrm{Si}$ la figura del periodista investigador desaparece de la realidad del norte fronterizo es posible que en el futuro los espacios de las ficciones sean los únicos donde los periodistas-detectives tengan posibilidades de sobrevivir.

\section{BiBLIOGRAFÍA}

Amparán, Francisco José. Algunos crímenesnorteños. Puebla/Zacatecas: Universidad Autónoma de Puebla/Universidad Autónoma de Zacatecas, 1992. Otras caras del paraíso. Nuevo León: Ediciones Castillo, 1995.

Bermúdez, María Elvira. Diferentes razones tiene la muerte: novela policíaca.

México: Talleres Gráficos de la Nación, 1953.

Muerte a la zaga. Tlahuapan, Puebla: Premiá, 1985.

${ }^{12}$ Blancornelas, Jesús, “Periodistas: Miedo al narco”. Zeta. Semana del 22-28 de julio de 2005, no. 1636.

13 Aunque agrega que algunos pocos periodistas, incluyéndose a sí mismo, continuarán investigando sobre el narcotráfico.

Revista Iberoamericana, Vol. LXXVI, Núm. 231, Abril-Junio 2010, 377-391
ISSN 2154-4794 (Electrónico) 
Blancornelas, Jesús. "Periodistas: Miedo al narco". Zeta (Semana del 22-28 de julio de 2005): 1636.

Buxó, Ramón P. ¡Crimen monstruoso!: un periodista descubre el tremendo parricidio en Mazatlán, prisión del periodista al denunciar al parricida y sus cómplices, historia verídica y comprobada de este crimen sensacional. México: Andrés Botas, 1911.

Caneyada, Imanol. Los ahogados no saben flotar. Hermosillo: Editora la voz de Sonora, 2000.

Capote, Truman. A sangre fría. Barcelona: Anagrama, 1991.

Castro-Gómez, Santiago. "Althusser, los estudios culturales y el concepto de ideología”. Revista Iberoamericana LXVI/193 (octubre-diciembre de 2000): 737-51.

Fernández, Salvador C. "Poder, prostitución y periodismo en Morena en rojo de Miriam Laurini.” El norte y su frontera en la narrativa policíaca mexicana. Juan Carlos Ramírez-Pimienta y Salvador C. Fernández, comps. México: Plaza y Valdés/Occidental College, 2005. 133-151.

Fourez, Cathy. "Quand Hercule et Sherlock se enchilan”. <http://perso.wanadoo. fr/arts.sombres/Detectives_mexicains.htm>

Guzmán Wolffer, Ricardo. La frontera huele a sangre. México: Lectorum, 2002.

Laurini, Miriam. Morena en rojo. México: Joaquín Mortiz, 1994.

Munguía Espitia, Jorge. “La vaquita marina en peligro de extinción”. Proceso 1409 (2 de noviembre de 2003): 77.

Munro, Guillermo. El Camino del Diablo. Hermosillo: Instituto Sonorense de Cultura, 1997.

No me da miedo morir. Hermosillo, Sonora: Edición del autor, 2003.

Ramírez Heredia, Rafael. Muerte en la carretera. México: Joaquín Mortiz, 1986. Taibo II, Paco Ignacio. Sueños de Frontera. México: Promexa, 1990.

Trujillo Muñoz, Gabriel. El festín de los cuervos. La saga fronteriza de Miguel Ángel Morgado. México: Norma Ediciones, 2002.

“Conflictos y espejismos: la narrativa policíaca fronteriza mexicana”. El norte y su frontera en la narrativa policíaca mexicana. Juan Carlos RamírezPimienta y Salvador C. Fernández, comps. México: Plaza y Valdés/Occidental College, 2005. 23-37.

Mezquite Road. México: Planeta, 1995.

Testigos de cargo. La narrativa policíaca mexicana y sus autores. Tijuana, Baja California, México: CNCA-CECUT, 2000.

Xanic, Alejandra. “¿Quién fue? A tres años del crimen de Benjamín Flores, persiste la incertidumbre”. Impunidad. <http://www.impunidad.com/cases/ benjaminfloresS.html>

Revista Iberoamericana, Vol. LXXVI, Núm. 231, Abril-Junio 2010, 377-391
ISSN 2154-4794 (Electrónico) 
